\title{
Role of Urokinase-Type Plasminogen Activator Receptors as an Early Detector for Treatment Outcome in Adult Acute Myeloid Leukemia in Egyptian Patients
}

\author{
Hanan R. Nassar ${ }^{1 *}$, Eman Z. Kandeel' ${ }^{2}$, Laila A. E. Hegazy³, Amany M. Helal ${ }^{1}$, \\ Tarek Darwish1, Soad A. Eltokhy² \\ ${ }^{1}$ Medical Oncology, $\mathrm{NCl}$, Cairo, Egypt \\ ${ }^{2}$ Clinical Pathology, $\mathrm{NCl}$, Cairo, Egypt \\ ${ }^{3}$ Clinical Pathology, Faculty of Medicine, Cairo University, Cairo, Egypt \\ Email: ${ }^{*}$ hhanan 67@yahoo.com
}

Received 28 August 2015; accepted 11 October 2015; published 14 October 2015

Copyright (C) 2015 by authors and Scientific Research Publishing Inc.

This work is licensed under the Creative Commons Attribution International License (CC BY). http://creativecommons.org/licenses/by/4.0/

cC) (7) Open Access

\begin{abstract}
Background: The urokinase-type plasminogen activator system which consists of a proteinase (the urokinase-type plasminogen activator, $\mathrm{UPA}$ ), a receptor (the urokinase-type plasminogen activator receptor UPAR or CD87) and inhibitors (PAI1) is enriched in several types of tumors and involved in proteolysis, cell migration and invasion. High expression of UPA and UPAR is associated with an increased relapse rate and shorter survival in breast cancer and colorectal carcinomas. Aims: This study shed light on the expression of uPAR in adult acute myeloid leukemia (AML) and its prognostic relevance. Methods: Peripheral blood and bone marrow samples are obtained from 54 newly diagnosed AML adult patients, 20 healthy controls stained with anti CD87 and estimated on flow cytometry. Results: CD87 expression was heterogeneous in different FAB subtypes of AML with high expression in monocytic leukemia (M4/M5) (P value 0.001). High expression of CD87 was associated with shorter survival and poor response to therapy $(P=0.028,0.002$ respectively $)$. The most discriminating cut off value of CD87 expression was $20 \%$, patients with less than $20 \%$ expression had 4.6 times better treatment outcome than those with more than or equal to $20 \%$. On the multivariate analysis, CD87 was the most significant single variable that affect treatment outcome compared to total leucocytic count, hemoglobin level, platelets count, cytogenetic and FLT expression. Summary/Conclusion: High CD87 expression is an independent prognostic parameter associated with poor response and shorter overall survival in adult AML patients.
\end{abstract}

\footnotetext{
${ }^{*}$ Corresponding author.
}

How to cite this paper: Nassar, H.R., Kandeel, E.Z., Hegazy, L.A.E., Helal, A.M., Darwish, T. and Eltokhy, S.A. (2015) Role of Urokinase-Type Plasminogen Activator Receptors as an Early Detector for Treatment Outcome in Adult Acute Myeloid Leukemia in Egyptian Patients. Journal of Cancer Therapy, 6, 963-970. http://dx.doi.org/10.4236/jct.2015.611104 


\section{Keywords}

\section{AML, Plasminogen, Survival, uPAR, CD87}

\section{Introduction}

Acute myeloid leukemia (AML) is a clonal hematopoietic stem cell malignancy with great heterogeneity. The prognostic prediction for AML had been improved immensely in the past decades, however, precise risk-stratification at diagnosis remained difficult. Meanwhile, molecular mechanisms in the etiology and progression of AML are still vague, and AML genomes are expected to lead to identification of even more prognostic markers [1].

The plasminogen activation cascade has been evaluated extensively in numerous physiological and pathological conditions [2], and its role in processes such as cell migration and tumor invasion is well studied. UPA3 acts mainly by activating plasminogen to proteolytically active plasmin when bound to its high affinity receptor, uPAR (CD87) [3]. Consequently, growing evidence has demonstrated that UPA and especially uPAR are also involved in other processes independent of plasmin formation, e.g., in proliferation, chemotaxis, and cell adhesion [4]-[7]. uPAR is expressed by leukocytes (including polymorphonuclear neutrophils, monocytes, macrophages, eosinophils, and activated T lymphocytes), endothelial cells, and fibroblasts. Among normal BM cells, uPAR is expressed on a fraction of myeloid precursors (promyelocytes, myelocytes, and metamyelocytes), monocytes and their precursors, but not on CD34 haematopoietic stem progenitor cells or circulating dendritic cell precursors or [7] [8]. During short-term liquid culture in the presence of cytokines, the number of CD34 cells decreases in parallel concomitant with an increase in the number of uPAR cells, which is also associated with a more differentiated morphology and phenotype [9]. UPAR is expressed in most solid cancers as well as in several hematologic malignancies including myeloproliferative disorders, acute leukemias (e.g. ALL, AML) and multiple myeloma. uPAR is an attractive target for the treatment of cancer not only because it seems to have multiple functional roles associated with tumor progression but also because its expression is restricted quite tightly to tumor tissue and it is rarely expressed in adjacent normal quiescent tissue. Cell surface CD87 has been measured by immunoblots, immunohistochemistry, flow cytometry and radio-labeled uPA binding [10]. Consequently, this work aimed at study the prognostic impact of CD87 in adult AML in relation to other prognostic parameters (Table 1).

\section{Patients and Methods}

EDTA blood samples were obtained from 54 adult AML patients, they were male to female ratio was 1.1:1 with median of 39 years (range 18 - 83). Patients were chosen from the medical oncology department of the National Cancer Institute, Cairo University from October 2012 to March 2013. Among the AML cases, (7) M1, (14) M2, (8) M3, (20) M4, (4) M5 and (1) was M7.Twenty normal subjects of matched age and sex were included as healthy controls for allogeneic bone marrow transplantation. Informed consents were obtained from each case. Patients were diagnosed and classified according to the consensus guidelines for immunologic diagnosis of acute leukemia and the 2008 Revision of WHO Classification of Tumors of Haematopoietic and Lymphoid Tissues [10]. Cut off of blast percentage considered $\geq 20 \%$.

\subsection{Sample Preparation and Staining Procedures}

For the detection of uPAR (CD87) expression, a PE-conjugated antibody (Clone VIM5) was used. The monoclonal used R-phycoerythrin (RPE) conjugated mouse anti-human monoclonal antibody clone VIM5 (Pharmamingen, Becton Dickinson, catalog number 33885X) react with the urokinase plasminogen activator receptor (UPAR), a 50-65 kD single chain glycosylphosphatidylinositol (GPI)-linked glycophorine. uPAR was clustered CD87 [11]. The whole blood lysis staining method was performed.

\subsection{Response to Treatment Was Classified as Follow}

\subsubsection{Good Prognosis}

Complete remission (CR) after two or more cycles of chemotherapy [Cellular marrow with $<5 \%$ blast cells, a 
Table 1. uPAR (CD87) expression in relation to other clinical and prognostic parameters.

\begin{tabular}{|c|c|c|c|c|c|c|}
\hline & \multicolumn{4}{|c|}{ CD87\% groups } & \multirow{3}{*}{$P$ value } \\
\hline & & \multicolumn{2}{|c|}{$\geq 20 \%$} & \multicolumn{2}{|c|}{$<20 \%$} & \\
\hline & & Count & $\%$ & Count & $\%$ & \\
\hline \multirow{3}{*}{ TLC groups } & Total & 22 & $100 \%$ & 32 & $100 \%$ & \\
\hline & $<100 \times 10^{9} / \mathrm{L}$ & 17 & 77.3 & 23 & 71.8 & 0.6 \\
\hline & $\geq 100 \times 10^{9} / \mathrm{L}$ & 5 & 22.7 & 9 & 28.2 & \\
\hline \multirow{2}{*}{$\mathrm{Hb} \%$} & $<7 \mathrm{gm} / \mathrm{dl}$ & 7 & $31.8 \%$ & 16 & $50.0 \%$ & \\
\hline & $\geq 7 \mathrm{gm} / \mathrm{dl}$ & 15 & $68.2 \%$ & 16 & $50.0 \%$ & 0.26 \\
\hline \multirow{2}{*}{ Platelets } & $<100 \times 10^{3} / \mathrm{mm}^{3}$ & 16 & $72.7 \%$ & 27 & $84.4 \%$ & \\
\hline & $\geq 100 \times 10^{3} / \mathrm{mm}^{3}$ & 6 & $27.3 \%$ & 5 & $15.6 \%$ & 0.32 \\
\hline \multirow{2}{*}{ Gender } & Female & 11 & $50 \%$ & 15 & $46.9 \%$ & \\
\hline & Male & 11 & $50 \%$ & 17 & $53.1 \%$ & 0.82 \\
\hline \multirow{2}{*}{ SPLEEN } & No & 14 & $63.6 \%$ & 18 & $56.3 \%$ & \\
\hline & Involved & 8 & $36.4 \%$ & 14 & $43.8 \%$ & 0.59 \\
\hline \multirow{2}{*}{ LIVER } & No & 14 & $63.6 \%$ & 20 & $62.5 \%$ & \\
\hline & Involved & 8 & $36.4 \%$ & 12 & $37.5 \%$ & 0.53 \\
\hline \multirow{2}{*}{ L.N } & No & 20 & $90.9 \%$ & 31 & $96.9 \%$ & \\
\hline & Involved & 2 & $9.1 \%$ & 1 & $3.1 \%$ & 0.56 \\
\hline \multirow{2}{*}{ CNS } & No & 22 & $100.0 \%$ & 29 & $90.6 \%$ & \\
\hline & Involved & - & - & 3 & $9.4 \%$ & 0.26 \\
\hline \multirow{4}{*}{ Cytogentic criteria } & Normal & 12 & $63.2 \%$ & 19 & $61.3 \%$ & \\
\hline & Unfavorable & 2 & $10.5 \%$ & 1 & $3.2 \%$ & 0.64 \\
\hline & Favourable & 5 & $26.3 \%$ & 11 & $35.5 \%$ & \\
\hline & M1 & 2 & $9.1 \%$ & 5 & $15.6 \%$ & \\
\hline \multirow{4}{*}{ FAB } & M2 & 1 & $4.5 \%$ & 13 & $40.6 \%$ & \\
\hline & M3 & 2 & $9.1 \%$ & 6 & $18.8 \%$ & \\
\hline & M4 & 12 & $54.5 \%$ & 8 & $25.0 \%$ & \\
\hline & M5 & 4 & $18.2 \%$ & & & $0.001^{*}$ \\
\hline \multirow{3}{*}{ CR } & M7 & 1 & $4.5 \%$ & & & \\
\hline & Not achieved & 19 & $86.4 \%$ & 14 & $45.2 \%$ & \multirow{2}{*}{$0.002^{*}$} \\
\hline & achieved & 3 & $13.6 \%$ & 17 & $54.8 \%$ & \\
\hline
\end{tabular}

TLC: total leukocyte count, LN: lymph node involvement, CNS: cerebrospinal fluid involvement, FAB: French American British classification of acute myeloid leukemia, CR: complete remission. 
neutrophil count $>1.5 \times 10^{9} / \mathrm{L}$ and no evidence of leukemia in other sites].

\subsubsection{Poor Prognosis}

Residual disease [Cellular marrow $>5 \%$ blast cells or evidence of leukemia in other sites] after two or more cycles of chemotherapy or died or relapsed during therapy within five months.

\subsection{Statistical Methods}

SPSS version 18.0 was used for data analysis. Mean \pm standard deviation described quantitative data. Qualitative data were expressed as percentages. Percentages were compared using Chi-square and Fisher-exact tests. Kaplan Meier method estimated survival and log rank test compared survival curves. $\mathrm{P}$ value is significant at 0.05 level.

\section{Results}

Surface expression of CD87 was analyzed in 54 de novo AML patients and 20 healthy controls.

\subsection{CD87 and Laboratory Data}

The number of cases expressing uPAR CD $87 \geq 20 \%$ of the gated cells, (Graf et al., 2005) in the whole group of acute leukemia patients was 22/54 (40.7\%) while 32/54 (59.3\%) were uPAR negative. Total leukocyte count TLC ranged from 2 to $380 \times 10^{9} / \mathrm{L}$ with a median $42.5 \times 10^{9} / \mathrm{L}$, HB ranged from 2.3 to $10 \mathrm{gm} / \mathrm{dl}$ with a mean 7.250 , PLT ranged from 4 to $275 \times 10^{3} / \mathrm{mm}^{3}$ with a median $42 \times 10^{3} / \mathrm{mm}^{3}$. No statistical significance was associated between the age, gender, TLC, HG nor PLT count. Cytogenetic information was available in 50 patients. Normal karyotype was found in 31/50 (62\%). Favorable cytogenetic were found in 16/50 (32\%), 5 cases t (8:21), 3 cases inv (16) and 8 cases t (15:17). Unfavorable cytogenetics as were found in 3/50 (6\%), one case t (9:11) and 2 cases t (9:22). FLT3 results were available in 47 patients. FLT3 was Mutant in 13/47 (27.7\%). FLT3 was Wild in 34/47 (72.3\%). Relationship between CD87 and FLT3 was statistically insignificant. CD87 was positive in 22/54 (40.7\%) cases of AML patients. CD87 positive blasts were found in 2/7 of M1, 1/14 of M2, 2/8 of M3, 12/20 of M4, all 4 cases of M5, and only one case of M7. In AML patients, whose blast cells show monocytic differentiation, CD87 was positive in 12/20 and 4/4 in M4 and M5 respectively. There were significant differences when CD87 negative was compared with CD87 positive in monocytic leukemia ( $P=0.001)$. CD34 was positive in 6/21 (28.6\%) and negative in 15/21 (71.4\%). CD117 was available in 40 cases and was positive in $27 / 40$ cases (67.5\%) and negative in 13/40 cases (32.5\%).There wasn't any statistical relation between CD87 expression and CD34 nor CD117 (Figure 1).

\subsection{CD87 and Clinical Data}

Hepatosplenomegaly was found in 32 (59\%) of patients, Lymph node involvement in 51 (94\%), CNS infiltration in 3 patients (5.5\%). There wasn't any statistical association between organomegaly nor CSF infiltration with CD87 expression. The Cytogenetic information was available in 50 patients. Normal karyotype was found in 31/50 (62\%). Favorable cytogenetic were found in 16/50 (32\%), 5 cases t (8:21), 3 cases inv (16) and 8 cases $t$ (15:17). Unfavorable cytogenetics as were found in 3/50 (6\%), one case t (9:11) and 2 cases t (9:22).

\subsection{CD87 and Treatment Outcome}

Comparison of the overall survival of the 22 AML patients showing CD87 positive expression with that of the 32 patients showing CD87 negative expression revealed a significant difference in survival with a median observation period of 30 days (range, 2 - 240 days) in this series. Survival analysis showed that the patients with CD87 positive expression had significantly shorter OS (median, 30 days) than the patients with CD87 negative expression (median, 90 days) $(\mathrm{P}=0.0248)$. Multivariate forward stepwise logistic regression was used to predict achievement of remission as an early response as well as treatment outcome (death/relapse) from a set of predictor independent prognostic criteria. Prognostic criteria in the study were included in the form of continuous variables (Hb, TLC, PLT, CD87\%, CD 34\%, CD117\%) and categorical data (Gender, FAB, Cytogenetic, FLT3, CSF infiltration, hepatomegaly, splenomegaly and lymph nodes involvement). The results revealed that CD87 


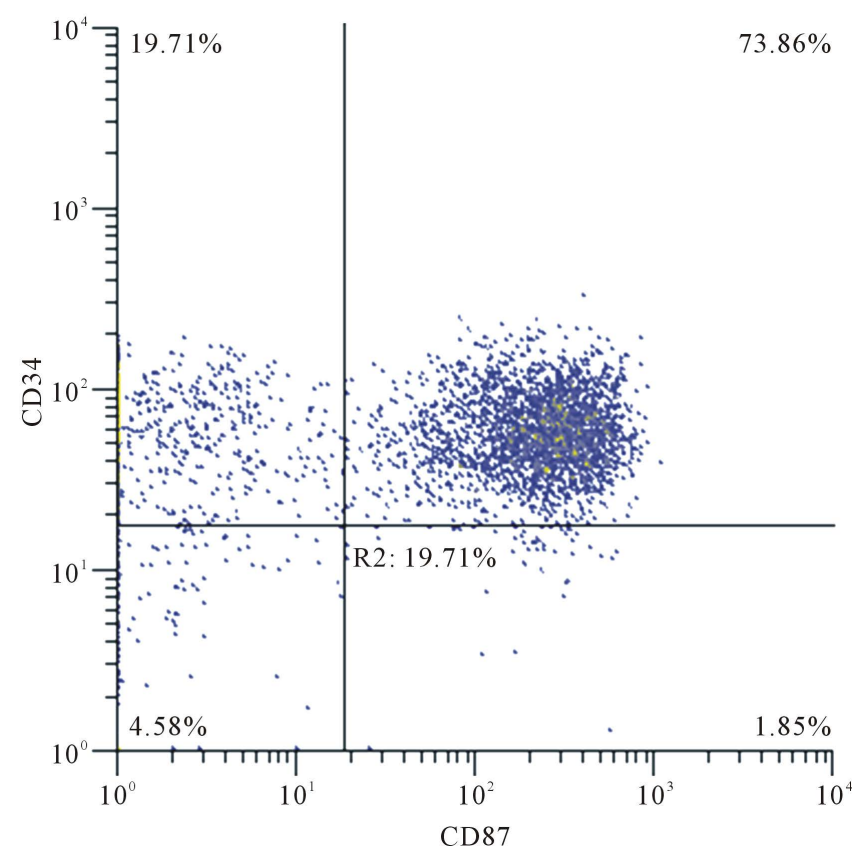

Figure 1. A case of acute myeloid leukemia showed co expression of CD34 and CD87.

expression $\geq 20 \%$ was the most significant predictor of $C R$ achievement $(P=0.002)$ compared to TLC $\geq 100 \times$ $10^{9} / \mathrm{L}(\mathrm{P}=0.02)$ and presence of splenomegaly $(\mathrm{P}=0.04)$. Regarding the treatment outcome CD87 expression $\geq 20 \%$ was the only significant predictor $(\mathrm{P}=0.007)$.

\section{Discussion}

The outcome of acute myelogenous leukemia (AML) is yet poor compared to acute lymphoblastic leukemia. Meticulous studying of new prognostic parameters and new therapeutic strategies are critically required. The urokinase-type plasminogen activator receptor (UPAR) has been implicated in signal transduction and biological processes including cancer metastasis, angiogenesis, cell migration, and wound healing. [12]. Increased levels of uPA, PAI-1 and uPAR have been reported to be associated with poor prognosis in patients with breast cancer and colorectal carcinomas [13].

The aim of this work was to assess the cell surface expression CD87 uPAR in patients with acute myeloid leukemia at initial diagnosis to shed light on the prognostic relevance of this marker in adult AML. This study included 54 newly diagnosed acute leukemia adult patients, they included 28 male and 26 female with an age range of 18 to 83 with a mean of $39.09 \pm 15$ and a median of 40 years. Criteria for diagnosis of acute leukemia were established according to the French-American-British (FAB) recommendations including morphology; together with cytochemistry and immunophenotyping of the leukemic blasts. Among the AML cases, (7) were M1 (13\%), (14) were M2 (25.9\%), (8) were M3 (14.8\%), (20) were M4 (37\%), (4) were M5 (7.4\%) and (1) was M7 (1.9\%). Patients were followed up to evaluate disease status for a period of 6 months. In the current study, the surface expression of uPAR on the peripheral blood leukemic blasts of patients with acute leukemia was evaluated by flow cytometry. A case was defined uPAR CD87 positive if $\geq 20 \%$ of the gated cells expressed uPAR [14] [15]. Although the expression of uPAR in blast cells are concerned, a little is known about its expression and prognostic value in AML patients. Lanza et al. (1998) found that 72.2\% of AML patients were positive for the anti-uPAR (CD87) MoAb [16]. The number of positive cases and the level of expression were significantly higher in AML patients belonging to the myeloid leukemia with monocytic differentiation FAB M4 and M5 subgroups, thus supporting the concept that a close association between monocytic commitment and expression of UPA-R may exist. In this study the highest rate of CD87 expression was observed in monoblastic AML \{12/22 patients in M4 (54.5\%) and all 4 cases of M5 (18.2\%)\}, while the lowest was found among patients with poorly differentiated AML $\{2$ cases M1 (9.1\%), 2 cases M3 (9.1\%), one case M2 and one case M7 (4.5\%)\}. 
This was statistically significant $(\mathrm{P}=0.001)$.

Similarly, Atfy et al. (2012) showed the highest rate of CD87 expression in monoblastic AML (33/36 and 22/23 patients in M4 and M5, respectively), while the lowest was found among patients with poorly differentiated AML (1/3 patients in M0 subtype) [17]. Lanza et al. (1998) showed that AML blasts displayed a heterogeneous pattern of expression of CD87, with reactivity strictly dependent on the type of cell involved (granulocytic or monocytic) and its degree of maturation [16]. Knapp et al. (1994) reported that CD87 expression was most frequently expressed in acute myeloid leukemia (AMLs) with monocytic differentiation (FAB M4 and M5), and it was co-expressed with CD14 in most positive cases [18]. We can conclude that many blasts from AML patients, especially from patients with monocytoid leukemia, show reactivity for the anti uPAR antibody, pointing to a possible association between a monocytic commitment and uPAR expression. This preferential expression in monocytoid leukemias was also supported by other authors as Aref et al. (2003) [19] and Nadir et al. (2005) [20]. Also, Scherrer et al. [1999] concluded that uPAR mRNA production of leukemic blast cells has been shown to be limited to FAB-classes M4-M5, as it was detected in 4/22 (18.2\%) cases of AML, all of them were M4-M5 subtype, while uPAR mRNA was not expressed by M0 cells [21]. Other studies like Plesner et al. (1994) found that uPAR (Clone R2 and R4 immunostaining of tissue samples) was expressed in 12 of 27 AML patients with different FAB subclasses. It was expressed in 3/4 M2 cases (75\%), 2/7 M4 (28.5\%) and 7/10 M5 (70\%) AML cases but not in FAB class M1 [22]. Jardi et al. (1996) found uPAR to be expressed only on the surfaces of the blast cells of the most mature myeloid leukemias M3 and M5 leukemia [23]. Our data revealed that 41/54 AML patients showed unfavorable outcome of which 36/54 died because of disease and 5/54 were lost during follow up (most probably died) while only 13/54 are alive. Among 22 CD87 positive cases, 3 cases (13.6\%) were alive, 18 cases (81.8\%) died. As regards achievement of CR among CD87 positive cases 19/22 (86.4\%) didn't achieve complete remission, on the other hand 17/31(54.8\%) achieved CR in CD87 negative cases. The association between positivity of CD87 and achievement of CR was statistically significant $(\mathrm{P}=$ 0.002). Similarily, Lanza et al. (1998) identified marked increase of uPAR receptors in a group of AML patients that relapsed following induction consolidation chemotherapy [16], and Graf et al. (2005) observed that a high expression rate of uPAR on AML cells was significantly correlated with lower remission rate $(P=0.03)$ [15]. As regards the correlation to clinical data and biological data we found no correlation between age, sex and surface uPAR which was in agreement with others as Atfy et al. (2012); Lanza et al. (1998); Rigolin et al. (2003) and Sawai et al. (2006) [16] [17] [24] [25].

In this study we correlated CD87 positivity and its impact on overall survival which revealed a significant difference in survival with a median observation period of 30 days (range, 2 - 240 days). Survival analysis showed that the patients with CD87 positive expression had significantly shorter overall survival(OS) (median, 30 days) than the patients with CD87 negative expression (median, 90 days) $(\mathrm{P}=0.0248)$. Atfy et al. (2012) [17] observed that a CD87 high expressions on AML cells were significantly correlated with shorter progress-free survival times more than CD87 low did $(P=0.0188)$, thus confirming data reported by other authors with respect to solid tumors as it facilitates tumor invasion and metastasis of solid malignant tumors. In our study, we correlated CD87 positivity with different antigens in AML cases as CD34 and CD117. CD34 was positive in 6/21 (28.6\%) CD87 positive patients, and CD117 was positive in 9/17(52.9\%) of CD87 positive patients. A comparison of antigen expression of CD117 between CD87positive and CD87negative AML revealed that CD117 was positive in 9/17 positive CD87 cases and was positive in 18/23 negative CD87 cases but there is no significant difference $(\mathrm{P}=0.09)$. However Atfy et al. (2012) [17] reported that the co-expression of CD34 with CD87 high was significantly associated with an unfavorable clinical course regard to OS $(P=0.01)$. In conclusion, there is a negative prognostic impact of the high expression of CD87 on the survival rate of AML patients, so it is an important prognostic marker in AML. Therefore, CD87 expression should be incorporated into the initial diagnostic work-up of AML patients as it was expressed in all AML patients. Further functional tests are necessary to elucidate the pathophysiological mechanisms behind these findings and to learn about the mechanism to influence the CD87 expression and function.

\section{References}

[1] Damm, F., Heuser, M., Morgan, M., Wagner, K., Gorlich, K., et al. (2011) Integrative Prognostic Risk Score in Acute Myeloid Leukemia with Normal Karyotype. Blood, 117, 4561-4568. http://dx.doi.org/10.1182/blood-2010-08-303479

[2] Pöllänen, J., Stephens, R.W. and Vaheri, A. (1991) Directed Plasminogen Activation at the Surface of Normal and Malignant Cells. Advances in Cancer Research, 57, 273-328. http://dx.doi.org/10.1016/S0065-230X(08)61002-7 
[3] Behrendt, N. and Stephens, R.W. (1998) The Urokinase Receptor. Fibrinolysis Proteolysis, 12, 191-204.

[4] Blasi, F. (1997) uPA, uPAR, PAI-1: Key Intersection of Proteolytic, Adhesive and Chemotactic Highways? Immunology Today, 18, 415-417. http://dx.doi.org/10.1016/S0167-5699(97)01121-3

[5] Aguirre-Ghiso, J.A., Kovalski, K. and Ossowski, L. (1999) Tumor Dormancy Induced by Downregulation of Urokinase Receptor in Human Carcinoma Involves Integrin and MAPK Signaling. The Journal of Cell Biology, 147, 89-103. http://dx.doi.org/10.1083/jcb.147.1.89

[6] Chapman, H.A. (1997) Plasminogen Activators, Integrins, and the Coordinated Regulation of Cell Adhesion and Migration. Current Opinion in Cell Biology, 9, 714-724. http://dx.doi.org/10.1016/S0955-0674(97)80126-3

[7] Gyetko, M.R., Todd, R.F., Wilkinson, C.C. and Sitrin, R.G. (1994) The Urokinase Receptor Is Required for Human Monocyte Chemotaxis in Vitro. The Journal of Clinical Investigation, 93, 1380-1387. http://dx.doi.org/10.1172/JCI117114

[8] Almeida, J. (1999) Extensive Characterization of the Immunophenotype and Pattern of Cytokine Production by Distinct Subpopulation of Normal Human Peripheral Blood MHC + Lineage Cells. Clinical \& Experimental Immunology, 188, 392-409. http://dx.doi.org/10.1046/j.1365-2249.1999.01078.x

[9] Plesner, T., Ralfkiaer, E., Wittrup, M., Ferrero, E., Bondanza, A., et al. (1994) Expression of the Receptor for Urokinase-Type Plasminogen Activator in Normal and Neoplastic Blood Cells and Hemopoietic Tissue. American Journal of Clinical Pathology, 102, 835-841.

[10] Ramage, J.G., Vallera, D.A., Black, J.H., Aplan, P.D., Kees, U.R., et al. (2003) The Diphtheria Toxin/Urokinase Fusion Protein (DTAT) Is Selectively Toxic to CD87 Expressing Leukemic Cells. Leukemia Research, 27, 79-84. http://dx.doi.org/10.1016/S0145-2126(02)00077-2

[11] Schlossman, S., Boumsell, L., Gilks, W., Harlan, J.M., Kishimoto, T., Morimoto, C., Ritz, J., Shaw, S. and Silverstein, R. (1995) Leucocyte Typing V: White Cell Differentiation Antigens. Oxford University Press, New York.

[12] de Bock, C.E., Lin, Z., Itoh, T., Morris, D., Murrell, G. and Wang, Y. (2005) Inhibition of Urokinase Receptor Gene Expression and Cell Invasion by Anti-uPAR DNAzymes in Osteosarcoma Cells. FEBS Journal, 272, 3572-3582. http://dx.doi.org/10.1111/j.1742-4658.2005.04778.x

[13] Han, B., Nakamura, M., Zhou, G.Y., Ishii, A., Nakamura, A., Bai, Y.H., et al. (2006) Calcitonin Inhibits Invasion of Breast Cancer Cells: Involvement of Urokinase-Type Plasminogen Activator (UPA) and uPA Receptor. International Journal of Oncology, 28, 807-814. http://dx.doi.org/10.3892/ijo.28.4.807

[14] Bene, M.C., Castoldi, G., Knapp, W., Rigolin, G.M., Escribano, L., Lemez, P., et al. (2004) CD87 (Urokinase-Type Plasminogen Activator Receptor), Function and Pathology in Hematological Disorders: A Review. Leukemia, 18, $394-$ 400.

[15] Graf, M., Reif, S., Hecht, K., Pelka-Fleischer, R., Pfister, K. and Schmetzer, H. (2005) High Expression of Urokinase Plasminogen Activator Receptor (UPA-R) in Acute Myeloid Leukemia (AML) Is Associated with Worse Prognosis. American Journal of Hematology, 79, 26-35. http://dx.doi.org/10.1002/ajh.20337

[16] Lanza, F., Matutes, E., Orfao, A., Knapp, W., Bene, M.C., et al. (1998) Expression and Functional Role of UrokinaseType Plasminogen Activator Receptor in Normal and Acute Leukemic Cells. British Journal of Haematology, 103, 110-123. http://dx.doi.org/10.1046/j.1365-2141.1998.00932.x

[17] Atfy, M., Eissa, M., Salah, H.E. and El Shabrawy, D.A. (2012) Role of Urokinase Plasminogen Activator Receptor (CD87) as a Prognostic Marker in Acute Myeloid Leukemia. Medical Oncology, 29, 2063-2069. http://dx.doi.org/10.1007/s12032-011-9993-x

[18] Knapp, W., Strobl, H. and Majdic, O. (1994) Flow Cytometric Analysis of Cell Surface and Intracellular Antigens in Leukemia Diagnosis. Cytometry, 18, 187-198. http://dx.doi.org/10.1002/cyto.990180402

[19] Aref, S., El-Sherbiny, M., Mabed, M., Menessy, A. and El-Rafaei, M. (2003) Urokinase Plasminogen Activator Receptor and Soluble Matrix Metalloproteinase 9 in Acute Myeloid Leukemia Patients: A Possible Relation to Disease Invasion. Hematology, 8, 385-391. http://dx.doi.org/10.1080/10245330310001621323

[20] Nadir, Y., Katz, T., Sarig, G., Hoffman, R., Oliven, A., Rowe, J.M., et al. (2005) Hemoststic Balance on the Surface of Leukemic Cells: The Role of Tissue Factor and Urokinase Plasmiongen Activator Receptor. Haematologica, 90, 15491556.

[21] Scherrer, A., Wohlwend, A., Kruithof, E.K.O., Vassalli, J.-D. and Sappino, A.-P. (1999) Plasminogen Activation in Human Acute Leukaemias. British Journal of Haematology, 105, 920-927. http://dx.doi.org/10.1046/j.1365-2141.1999.01432.x

[22] Plesner, T., Ralfkiaer, E., Wittrup, M., Johnsen, H., Pyke, C., Pedersen, T.L., et al. (1994) Expression of the Receptor for Urokinase-Type Plasminogen Activator in Normal and Neoplastic Blood Cells and Hemopoietic Tissue. American Journal of Clinical Pathology, 102, 835-884. 
[23] Jardi, M., Ingles-Esteve, J., Burgal, M., Azqueta, C., Velsaco, F., López-Pedrera, C., et al. (1996) Distinct Patterns of Urokinase Receptor (uPAR) Expression by Leukemic Cells and Peripheral Blood Cells. Thrombosis and Haemostasis, 76, 1009-1019.

[24] Rigolin, G.M., Tieghi, A., Ciccone, M., Bragotti, L.Z., Cavazzini, F., Della Porta, M., et al. (2003) Soluble Urokinasetype Plasminogen Activator Receptor (suPAR) as an Independent Factor Predicting Worse Prognosis and Extra-Bone Marrow Involvement in Multiple Myeloma Patients. British Journal of Haematology, 120, 953-959. http://dx.doi.org/10.1046/j.1365-2141.2003.04176.X

[25] Sawai, H., Okada, Y., Funahashi, H., Matsuo, Y., Takahashi, H., Takeyama, H. and Manabe, T. (2006) Interleukin-1 $\alpha$ Enhances the Aggressive Behavior of Pancreatic Cancer Cells by Regulating the $\alpha 6 \beta 1$-Integrin and Urokinase Plasminogen Activator Receptor Expression. BMC Cell Biology, 7, 8. 